National Voluntary

Laboratory Accreditation Program

U.S. DEPARTMENT OF COMMERCE National Bureau of Standards

\title{
Acoustics LAP Handbook
}

\section{OPERATIONAL AND TECHNICAL REQUIREMENTS OF THE \\ LABORATORY ACCREDITATION PROGRAM FOR \\ ACOUSTICAL TESTING SERVICES}

\section{NBSIR 85-3199}

U.S. DEPARTMENT OF COMMERCE National Bureau of Standards

U.S. DEPARTMENT OF COMMERCE National Burea's of Standards Office of Product Standards Policy Gaithersburg, Maryland 20899 



\section{ACOUSTICS LAP HANDBOOK OPERATIONAL AND TECHNICAL REQUIREMENTS OF THE \\ LABORATORY ACCREDITATION PROGRAM \\ FOR \\ ACOUSTICAL TESTING SERVICES}

NBSIR 85-3199

Robert L. Gladhill Wiley A. Hall, Jr. Jeffrey Horlick Harvey W. Berger

U.S. DEPARTMENT OF COMMERCE

National Bureau of Standards

Office of Product Standards Policy

Gaithersburg, Maryland 20899

July 1985

U.S. DEPARTMENT OF COMMERCE, Malcolm Baldrigo, Secrotary NATIONAL BUREAU OF STANDARDS. Emest Ambler. Director 



\section{Table of Contents}

$\underline{\text { Page }}$

I. THE ACOUSTICS lap at A GlanCE. .......... 1

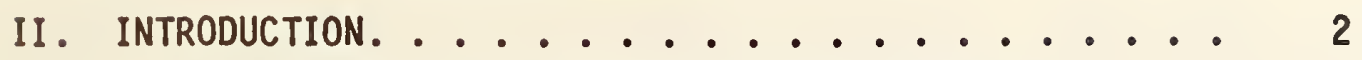

III. ADMINISTRATIVE AND OPERATIONAL REQUIREMENTS. . . 4

Laboratory Code Number ........... . 4

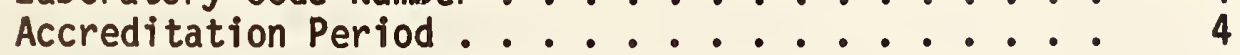

Renewal................ 4

Publicizing Accreditation Status ...... 4

By NVLAP

By Laboratories

Compliance with Existing Laws. ........ 5

Accreditation Process. . . . . . . . . 5

Application and Fees

Approved Signatory

Technical Experts

On-site Assessment

Monitoring Visits

Proficiency Testing

Technical Evaluation

Administrative Review

Accreditation Actions. ......... 10

IV. TECHNICAL REQUIREMENTS ............ 11

Scope of LAP .................... 11

Quality Assurance System ........... 11 Documentation

Personnel

Equipment and Facilities

Equipment Maintenance and Calibration

Recordkeeping

Test Report. ............. 15

v. PROFICIENCY TESTING. ................ 15

APPENDICES

NVLAP Accreditation Criteria (December 1984)

NVLAP Lab Bulletin No. 3A

Test Method List 



\section{THE ACOUSTICS LAP AT A GLANCE}

This document presents the operational and technical requirements of the Laboratory Accreditation Program (LAP) for acoustical testing services. All of the steps leading to accreditation are described. Technical requirements are explained indicating how the NVLAP criteria are applied.

The laboratory accreditation program for acoustical testing services (Acoustics LAP) was established in 1982 in response to a request from a manufacturer of acoustical absorption materials. The purpose of the LAP is to give national recognition, through accreditation, to those laboratories found competent to perform specified tests on acoustical materials.

Accreditation is available to any organization including, commercial laboratories, manufacturer's laboratories, Federal, state, or local government laboratories that test acoustical materials using the test methods listed in the Appendix.

Period of accreditation: One year

On-site assessment frequency: Prior to initial accreditation and every two years thereafter

Proficiency testing: Required periodically. Test methods subject to proficiency testing are shown with an asterisk in the Appendix.

Fees: Administrative fee, one-time initial fee, and total test method fee based on the number of test methods selected. 


\section{INTRODUCTION}

\section{Background}

The U.S. Department of Commerce, National Bureau of Standards (NBS) administers the National Voluntary Laboratory Accreditation Program (NVLAP). NVLAP's function is to accredit public and private testing laboratories based on evaluation of their technical qualifications and competence for conducting specific test methods in specified fields of testing. Accreditation is granted on the basis of conformance with criteria published in the Code of Federal Regulations as part of the NVLAP procedures (15 CFR Part 7). (See Appendix.)

This document is intended for use by staff of accredited laboratories, those seeking accreditation, other laboratory accreditation systems, and others needing information on the requirements for NVLAP accreditation under this LAP. This document is generally included in the NVLAP Application Package along with General Application Forms, Test Method Selection Lists, and other materials needed to apply for or renew accreditation. It presents the administrative and operational procedures and technical requirements of the LAP and should be retained and be readily accessible to laboratory personnel.

NVLAP Accreditation

Accreditation is granted only after thorough evaluation of the applicant has demonstrated that all NVLAP criteria have been met. The accreditation is formalized through issuance of a Certificate of Accreditation, Scope of Accreditation and publicized by announcement in various government and private media.

NVLAP accreditation is available to comercial laboratories, manufacturer's in-house laboratories, university laboratories, Federal, State, and local government laboratories. Foreign- based laboratories may also be accredited by NBS if they meet the same requirements as domestic laboratories and pay any additional fees required.

Why NVLAP Accreditation ?

The reasons why a laboratory may wish to be accredited include: legal requirements such as regulations or codes, contract specifications, and the desire to be recognized as being demonstrably competent to meet the needs of its clients.

For accreditation to be meaningful, it must be granted by a clearly credible organization. NVLAP provides an unbiased third party evaluation and recognition of performance as well as expert technical assistance to upgrade 1 aboratory performance. 


\title{
Testing Laboratory Defined
}

NVLAP defines a "testing laboratory" as an organization that provides services to measure, examine, test, calibrate, or otherwise determine the characteristics or performance of products or systems.

\section{Accreditation Defined}

NVLAP accreditation means recognition of a testing laboratory's competence to perform specific test methods in specified fields of testing. It means that the laboratory's quality system, staff, facilities and equipment, calibration procedures, test methods and procedures, records, and test reports, have been evaluated and found to meet NVLAP criteria. NVLAP accreditation does not mean a guarantee (certification) of laboratory performance or product test data; it is a finding of laboratory competence.

For further information about NVLAP, or assistance in understanding and meeting the NVLAP requirements and criteria, please write or call:

\section{NVLAP}

\author{
National Bureau of Standards \\ ADMIN A531 \\ Gaithersburg, MD 20899 \\ Phone: $301-921-3431$
}




\section{ADMINISTRATIVE AND OPERATIONAL REQUIREMENTS}

Note: Administrative and operational requirements presented here are generally applicable to all NVLAP programs. Technical and proficiency requirements are specifically applicable to this LAP.

\section{LABORATORY CODE NUMBER}

Each participating laboratory is assigned a four-digit laboratory code number. The code number is used by the NVLAP staff for identification, filing, recordkeeping, and database management. Participants are requested to put their Lab Code number on all correspondence with NVLAP.

\section{ACCREDITATION PERIOD}

Accreditation is granted for a period specified in the LAP Application Package (usually one year). The accreditation period begins on one of four dates: January 1, April 1, July 1, or October 1. Once a laboratory has been assigned an accreditation date, it retains that date as long as it remains in the program. Accreditation expires and is renewed on that date.

\section{RENEWAL}

Each participating laboratory will be sent a renewal Application Package, well in advance of the expiration date of $i$ ts accreditation, to allow sufficient time to complete the renewal process. The renewal application contains the same forms used for initial application, and the laboratory need only indicate where changes have occurred from the previous period in personnel, equipment, facilities, or the scope of accreditation desired.

With the exception of an initiation fee for new applicants, the technical requirements and fees are the same as for initial accreditation. The application and fees must be received by NBS prior to expiration of the Taboratory's current accreditation to avoid a lapse in accreditation.

\section{PUBLICIZING ACCREDITATION STATUS}

\section{BY NVLAP}

NVLAP publishes an annual Directory of Accredited Laboratories. The Directory contains the name and address, scope of accreditation, contact person, and the accreditation renewal date for each accredited laboratory. Supplements to the Directory are published quarterly to cover interim accreditation actions including initial accreditations, renewals, suspensions, terminations, and revocations. The Directory is distributed nationally and internationally to manufacturers, suppliers, retailers, professional and trade associations, code groups, and government agencies. 
Accredited laboratories are encouraged, within specified limits, to publicize their accredited status. The major restriction is that advertising must not imply product certification by NBS or the U.S. Government. Laboratories and their clients may not reference their accredited status in consumer media, in product advertising, or on product labels, containers or packaging.

A 1 aboratory may cite its accredited status and use NVLAP logos on reports, stationery, and in business and trade publications provided that it is clearly indicated that it is the laboratory which is accredited. NVLAP Lab Bulletin No. 3A provides more detailed guidance on how a laboratory may publicize its accredited status and the statements which may be made. (See Appendix.)

\section{COMPLIANCE WITH EXISTING LAWS}

Accreditation does not relieve the laboratory of the need to observe and comply with existing Federal, State, and local statutes, ordinances, or regulations that may be applicable to its operations, including consumer protection and antitrust 1 aws.

\section{ACCREDITATION PROCESS}

Accreditation is granted following successful completion of a process which includes submission of an application and payment of fees by the laboratory, an on-site assessment, resolution of deficiencies identified during the on-site assessment, participation in proficiency testing, technical evaluation, and administrative review. A diagram of the accreditation process is shown in the figure below.

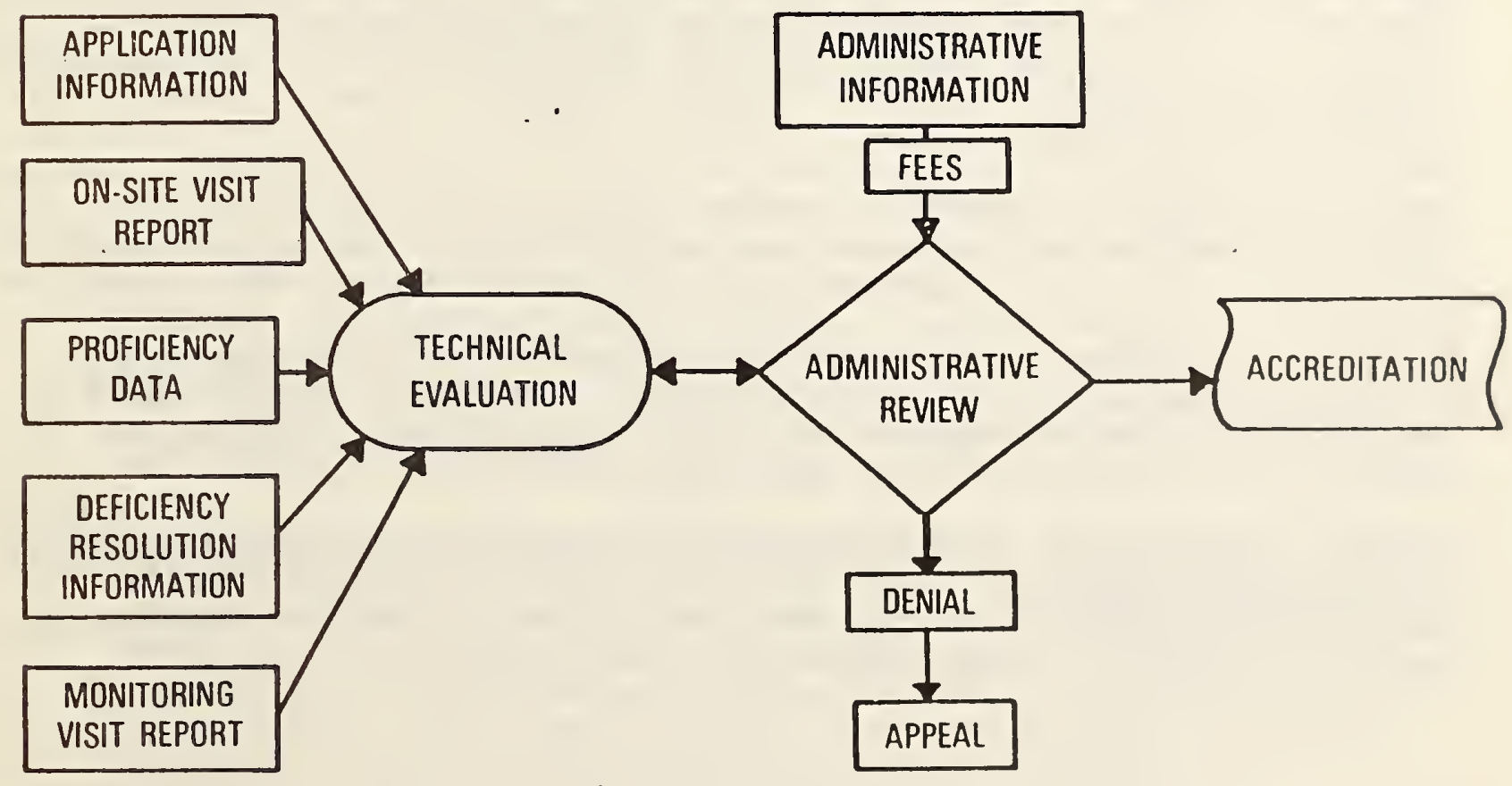


An Application Package is sent to a laboratory on request. It includes: General Application Forms, a Fee Calculation Sheet, and this document. The General Application Form must be completed and signed by an authorized representative of the 1 aboratory. The authorized representative is one who can act on behalf of the laboratory and commit it to fulfill the NVLAP requirements. Before completing and signing the application, the authorized representative should review all documents and become totally familiar with NVLAP requirements. Al though other laboratory staff may be designated to perform activities, such as handling proficiency testing or receiving an assessor, the authorized representative is the only one who can authorize a change in the scope or nature of the application.

In general, the accreditation fee is composed of several parts, some of which are fixed while others depend on the scope of accreditation desired and the specifics of the LAP. The total accreditation fee must be paid before accreditation can be granted. The individual parts of the accreditation fee include, as appropriate: a one-time LAP initiation fee for new applicants, an administrative fee, test method fees, an assessment fee, and proficiency testing fees. The fees for this LAP are shown in the Fee Calculation Sheet included in the LAP Application Package.

The laboratory will be scheduled for an on-site assessment after payment of all required fees and will be notified of any additional information which must be supplied and of any applicable proficiency testing requirements which must be completed for the technical evaluation.

\section{APPROVED SIGNATORY}

Under NVLAP criteria, an accredited laboratory must have one or more individuals or laboratory positions designated as having responsibility for signing "all test reports endorsed with the NVLAP 10go." This is the person(s) to whom NVLAP, Taboratory clients, or others would go in case of questions or problems with the report.

There is no formal requirement for nomination or approval of persons or laboratory positions designated as approved signatories. The laboratory should inform NVLAP of its appointments by completing the appropriate sections in the application for accreditation. Approved signatories should be: persons or positions with adequate responsibility or authority within the organization, wi th adequate and appropriate technical capabilities, and without conflict of interest. The approved signatory may be the authorized representative who is responsible for signing the NVLAP Application Form.

Laboratory test reports carrying the NVLAP logo need not be signed individually by the approved signatory. Test report forms may be preprinted with the required information. Forms that are electronically or computer generated may have the information printed along with the test results. 
NVLAP uses Technical Experts (TES) as assessors and evaluators. These are individuals knowledgeable in the testing field being evaluated. They may be engineers or scientists currently active in the field, consultants, college professors or retired persons. They are selected on the basis of their professional and academic achievements, experience in the field of testing, management experience, and tact in dealing wi th people. Their services are generally contracted as required; they are not NVLAP staff members.

Assessors are TEs selected to conduct an on-site assessment of a particular Taboratory on the basis of how well their individual experience matches the type of testing to be assessed, as well as absence of conflicts of interest. The laboratory has the right to appeal the assignment of an assessor and may request an alternate.

Evaluators are TEs selected to review the record of the laboratory as a whole, including the application, assessment report, deficiencies, corrections to deficiencies, and proficiency test results and, based on this record, to recommend whether or not a laboratory should be accredited. The evaluators are matched to the type of testing being evaluated and are selected to avoid conflicts of interest.

\section{ON-SITE ASSESSMENT}

Before initial accreditation and periodically thereafter, an on-site assessment of each laboratory is conducted to determine compliance with the NVLAP criteria. The assessment is conducted by one or more NVLAP assessors selected on the basis of their expertise in the field of testing to be reviewed. Assessors use checklists developed by NVLAP so that each laboratory receives an assessment comparable to that received by others. However, assessors have considerable latitude to make judgments about a laboratory's compliance with the NVLAP criteria, depending on the assessor's experience and the unique circumstances of the laboratory.

Each laboratory will be contacted to arrange a mutually agreeable date for an asessment. The time needed to conduct an assessment varies, but two days is the norm. Every effort is made to conduct an assessment with as little disruption as possible to the normal operations of the laboratory. During the assessment the assessor will carry out the following functions:

- meet with management and supervisory personnel responsible for the laboratory's activities (for which accreditation is being sought) to review the assessment process with the individuals involved and to set the assessment agenda.

- examine the quality assurance system employed by the laboratory. The assessor may select and trace the history of one or more samples from receipt to final issuance of test reports. The assessor will conduct a thorough review of the laboratory's quality manual or equivalent, evaluate the training program, examine notebooks or records pertaining to the samples, check sample identification and tracking procedures, determine whether the appropriate environmental conditions are maintained, and examine copies of completed test reports. 
- review records of periodic internal audits, use of check samples or participation in round robin testing or other similar programs.

- review personnel records including resumes and job descriptions of key personnel, competency evaluations for all staff members who routinely perform the testing for which accreditation is sought, calibration or verification records for apparatus used, test reports, and sample control records.

- observe demonstrations of testing techniques and discuss them with the technical personnel to assure their understanding of the procedures.

- examine major equipment, apparatus, and facilities.

At the conclusion of the assessment, the assessor will conduct an exit briefing to discuss his or her observations with appropriate laboratory staff and call attention to any deficiencies uncovered. A written summary of any deficiencies discussed will be left at the laboratory. The assessor will forward the assessment forms and a written summary to NBS.

If deficiencies have been noted, the laboratory
must, within 30 days of the date of this
notification provide NVLAP with documentation or
certification, by the authorized representative,
that the specified deficiencies have been
corrected or that specific actions are being
taken to correct the deficiencies.

A 1 aboratory applying for initial accreditation may request an extension to complete required corrections.

If any deficiencies are noted at laboratories which are currently accredited, such deficiencies must be corrected within 30 days after notification or the laboratory may face possible revocation, suspension, or expiration of its accreditation. Any test equipment that is identified as out-of-calibration, should not be used until corrective action has been completed. All

deficiencies noted for corrective action will be subject to thorough review and verification during subsequent assessments and technical evaluations.

\section{MONITORING VISITS}

In addition to regularly scheduled assessments, monitoring visits may be conducted by assessors or by NBS staff at any time during the accreditation period. Monitoring visits may occur for cause or on a random selection basis. These visits serve to verify reported changes in the 1 aboratory's personnel, facilities, and operations or to explore possible reasons for poor performance in proficiency testing.

The scope of a monitoring visit may range from checking a few designated items to a complete review. Failure to cooperate with NVLAP assessors will be grounds for initiation of adverse accreditation action. No additional fee is required for the monitoring visit. 
Proficiency testing is an integral part of the NVLAP accreditation process. Demonstration of appropriate facilities, equipment, personnel, etc. is essential, but may not be sufficient for the evaluation of laboratory competence. The actual determination of test data using special proficiency testing samples provides NVLAP with a way to determine the overal1 effectiveness of the 1aboratory.

Proficiency testing is a process for checking actual laboratory testing performance, usually by means of interlaboratory comparisons. Each LAP has unique proficiency testing requirements. The data are analyzed by NVLAP and summary reports of the results are sent back to the participants.

For many test methods, results from proficiency testing are very good indicators of a laboratory's testing capability. Information obtained from proficiency testing helps to identify problems in a laboratory. When problems are found, NVLAP staff members work with the laboratory staff to solve them. If problems with the test method are suspected, NVLAP provides information to the appropriate standards-writing bodies.

The specific proficiency testing requirements for this LAP are included in Section $V$ of this document.

\section{TECHNICAL EVALUATION}

After a laboratory has completed all the technical requirements of a LAP and is ready for an accreditation action, a final technical evaluation is conducted by experts chosen for their experience and knowledge of the pertinent test methods. They review records on each applicant laboratory and base their evaluation on:

- information provided on the application;

- on-site assessment reports;

- actions taken by the laboratory to correct deficiencies;

- results of proficiency testing; and

- information from any monitoring visits of the laboratory.

If the technical evaluation reveals additional deficiencies, written notification describing them will be made to the laboratory. The laboratory must respond within 30 days of such notification and provide documentation or certification by the authorized representative that the specified deficiencies have been corrected. Clarification of some issues may be requested by telephone. All deficiencies must be corrected before accreditation can be granted or renewed. 


\section{ADMINISTRATIVE REVIEW}

After the technical evaluation has been completed, the NVLAP staff prepares an administrative recommendation that the 1 aboratory either be granted or denied accreditation. This recommendation is based on a review of the technical evaluation and other records to ensure that all NVLAP technical, financial and administrative obligations have been satisfied.

\section{ACCREDITATION ACTIONS}

Acting for the Director of NBS, the Director of the NBS Office of Product Standards Policy makes the following decisions.

Accreditation If accreditation is recommended, the recommendation forms the basis for granting accreditation. A Certificate of Accreditation will be issued to the laboratory.

Denial If denial is recommended, the laboratory is notified of a proposal to deny accreditation and the reason(s) therefor.

Suspension If a laboratory is found to have violated the terms of its accreditation, the accreditation can be suspended. The laboratory will be notified of the reasons for and conditions of the suspension and the action(s) that the 1 aboratory must take to have accreditation reinstated.

Revocation If a laboratory is found to have violated the terms of its accreditation, the laboratory is notified of a proposal to revoke accreditation and the reasons therefor. The laboratory may be given the option of voluntarily terminating accreditation. If accreditation is revoked, the laboratory must return its Certificate of Accreditation and cease use of the NVLAP logo on any of its reports, other correspondence, or advertising.

If denial or revocation has been proposed, the laboratory may request a hearing, under United States Code 5 U.S.C. 556, within 30 days of the date of receipt of the notification. If a hearing is not requested, the action becomes final upon the expiration of that 30-day period.

After a participant's accreditation has been terminated, whether voluntarily or through adverse action, the accreditation certificate must be returned to NVLAP. If a laboratory elects not to renew or wishes to voluntarily terminate its accreditation at any time, the notification of such intention should be forwarded to NBS in writing. 


\section{TECHNICAL REQUIREMENTS}

The requirements discussed in this section interpret the NVLAP criteria for application to the Acoustics LAP. These requirements do not supersede the published NVLAP criteria which are included in the Appendix.

\section{SCOPE OF THE LAP}

A laboratory may be accredited to perform any combination of tests selected from the list of test methods in the Appendix. In some cases a laboratory may be accredited to perform only selected parts of a test method. The test methods are grouped in two categories: precision test methods and engineering test methods.

\section{QUALITY ASSURANCE SYSTEM}

The key to a properly functioning organization is that it has and maintains a system of procedures and practices which assure the quality of its services. To qualify for accreditation, an applicant must demonstrate that its quality assurance systems ensure the technical integrity of its work.

\section{DOCUMENTATION}

A laboratory must have up-to-date documentation which thoroughly describes all of its procedures and practices. The written descriptions should contain such items as the method of implementation, responsible personnel, recordkeeping system, operating procedures, procedures to employ in the event of unusual or non-standard circumstances, and scheduling. Written descriptions should include at least the following topics:

- Organizational chart;

- Laboratory facilities and scope of services offered;

- Job/position description for all personnel;

- Personnel training procedures;

- Personnel competency assurance procedures;

- Test equipment inventory;

- Test equipment calibration, verification, and maintenance practices;

- Test performance plan;

- Specimen selection, handling, analysis, control, and identification;

- Data handiing and reporting;

- Internal checks and audits;

- External standardization practices;

- Reference standards and/or materiais; and

- Subcontracting practices and procedures for assuring quality 
This documentation should be in the form of a manual but may be individual sheets in various locations throughout the facility. If individual sheets are used, a central reference document must be available to indicate where the sheets may be found. The documentation must be in a format and style which can be easily understood by technicians. It must be readily accessible to all staff members.

The laboratory's documentation must contain the latest published versions of the test method(s) for which accreditation is sought.

\section{PERSONNEL}

Training:

Each new staff member must be trained for assigned duties and existing staff members must be retrained when testing equipment and/or protocols are changed or they are assigned new responsibilities. Each staff member must receive (or have had) training for assigned duties either through on-the-job training, formal classroom sessions or through technician certification programs.

\section{Competency:}

In addition to training, the supervisor must evaluate the competency of each staff member by observing the performance of each testing protocol each staff member is authorized to conduct. The performance observation must be conducted annually by the immediate supervisor or his designee. A record of the staff member's performance must be $\mathrm{pl}$ aced in the personnel file, dated and signed by the supervisor.

Technical Director:

The laboratory technical director shall be a professional experienced in the testing area for which accreditation is desired. This individual should have the technical competence and the supervisory responsibility to direct the work of professionals and technicians in the appropriate area. Responsibility for the quality assurance program may reside with the technical director or with another individual having knowledge and experience in quality assurance who has a direct line of communication to the technical director and other organizational management.

The assessor wili review resumes or other information to substantiate the qualifications of the Technical Director and all key individuals.

Any organizational or personnel changes that could affect the performance of the testing service (e.g., Technical Director, technical supervision, responsibility for quality assurance program) shall be reported to NVLAP within 30 calendar days of such change. 


\section{EQUIPMENT AND FACILITIES}

A laboratory must have adequate equipment to perform the type(s) of testing for which capability is claimed. This includes the space needed to perform the testing, environmental controls, suitable testing equipment, appropriate safety systems and either properly calibrated laboratory standards or access to the services of a competent calibration laboratory.

\section{EQUIPMENT MAINTENANCE AND CALIBRATION}

A11 equipment used in the testing of acoustical materials and to perform quality control must be properly maintained so that it can accomplish the required measurements.

Measurement or quality control equipment that is inherently subject to change due to use or passage of time must be periodically calibrated. Calibration means comparison with a reference standard so that the performance of a measuring instrument may be determined with sufficient accuracy. The equipment used for conducting measurements must be maintained and calibrated (or verified) in accordance with the manufacturer's recommendations, as specified in the test method, or as specified as follows, whichever frequency is greater.

\section{Apparatus/Instrumentation}

Acoustic calibrators or pistonphones

Balances

Engine-speed tachometers

Filter sets (octave-band and one-third octave-band)

Flowmeters (air)

Frequency analyzers

Frequency counters

Force gauges

Oscillators

Reference microphones

Reference sound sources

(calibration in accordance with ANSI S1.35 or ISO 3745)

Tape recorders or graphic level recorders

Test signal (pink noise) generators

Test signal (pure tone) generators

Timers

Wave-form generators

Hygrometers

Temperature recorders or thermocouples

Pressure measuring devices (air)
Calibration or
Verification
Frequency

annually

annually

annually

annually

annually

annually

annually

annually

annually

annually

annually

annually

annually

annually

annually

annually

semi-annual 1y

semi-annua $17 y$

semi-annual ly 
Voltmeters (precision)

Environment chambers

(temperature and humidity)

Loudspeakers for ANSI S1.32 or ISO 3742

Pick-up transducer systems

(generator, amplifier, recorder, etc.) once a year for ASTM Test Method E756 only.

Reflectometers

Sound measurement systems

Sound pressure level meters semi-annually

semi-annually for ASTM

Test Method E756 only.

during each test room qualification

spot-check prior to each test, full calibration

check calibration before each test

calibrate before and after each test series using an acoustical calibrator or pistonphone

same as above

Calibrations of equipment may be performed by the laboratory or by an external calibration service. All calibrations and characterizations must be done against reference standards that are traceable to national standards maintained by NBS or by an equivalent foreign national standards authority. To be traceable means the ability to show that appropriate documented actions were taken to compare (either directly or indirectly) a reference standard with a national standard.

The reference standards used and the environmental conditions at the time of calibration must be documented for all calibrations. Calibration records and evidence of the traceability of the reference standards used must be made available for inspection during the on-site visit.

Testing equipment or verification records should include the following: equipment name or description; model, style, or serial number; manufacturer; notation of all equipment variables requiring verification; the range of verification; the resolution of the instrument and its allowable error; verification date and schedule; date and result of last calibration; identity of the laboratory individual or external service responsible for calibration; source of reference standard and traceability.

\section{RECORDKEEPING}

A laboratory must maintain a functional recordkeeping system. This means that records must be easily accessible, in some logical order and contain complete information on the subject. Records covering the following items are required and will be reviewed during the on-site visit either in total or by selected sampling: 
- Staff training dates and results;

- Staff competency review dates and results;

- Testing equipment calibration and maintenance;

- Results of incoming inspection of materials;

- Comprehensive logs of test activities;

- Results of internal and external equipment checks, measurement assurance programs, quality audits, etc.;

- Test data and reports; and

- Tracking and logging of samples tested.

Sample tracking and logging records should trace the movement of each sample through the testing facility from its receipt through all the tests performed to the final test report. Dates, times, condition of item and personnel involved should all be included.

\section{TEST REPORT}

The test report to the client must include:

- Name and address of 1 aboratory;

- Pertinent dates and identifying numbers;

- Client name;

- Description or identification of each sample;

- Identification of the test method, procedures, or specifications;

- Identification of known deviations, additions to, or exclusions from the test method;

- Measurements, examinations, or derived results, and identification of test anomalies;

- A statement, if necessary, as to whether or not the test results comply with the requirements of product or project specifications;

- Name of person having technical responsibility for the test report; and

- A11 other items required by the test method.

Records of these reports must be maintained for at least three years.

\section{PROFICIENCY TESTING}

Proficiency testing is an integral requirement of the NVLAP evaluation process. Proficiency testing will be required periodically. The test methods subject to proficiency testing are identified by an asterisk in the test method 1 ist in the Appendix. Participants in the LAP will be informed when testing is required and will be sent appropriate materials, instructions, and data sheets. 



\section{APPENDICES}

NVLAP Accreditation Criteria

NVLAP Lab Bulletin No. 3A

Test Method List 



\section{NVLAP Accreditation Criteria \\ SUBPART D - CONDITIONS AND CRITERIA FOR ACCREDITATION}

Sec. 7.31 Application of accreditation conditions and criteria.

(a) To become accredited and maintain accreditation, a laboratory must meet the conditions for accreditation set out in Section 7.32 and the criteria set out in Section 7.33 as tailored for specific LAPs.

(b) The conditions leading to accreditation include acceptance of the responsibilities of an accredited laboratory and requirements for information disclosure.

(c) The criteria are tailored and interpreted for the test methods, types of test methods, products, services or standards of the relevant LAP. These tailored criteria are the technical requirements for accreditation developed through the procedures of Section 7.15.

(d) In applying the conditions, criteria, and technical requirements for accreditation, the Director of OPSP shall not:

(1) Prohibit accreditation solely on the basis of a laboratory's affiliation or nonaffiliation with manufacturing, distributing, or vending organizations, or because the laboratory is a foreign firm; or

(2) Develop, modify, or promulgate test methods, standards, or comparable administrative rules.

Sec. 7.32 Conditions for accreditation.

(a) To become accredited and maintain accreditation, a laboratory shall agree in writing to:

(1) Be assessed and evaluated initially and on a periodic basis;

(2) Demonstrate, on request, that it is able to perform the tests representative of those for which it is seeking accreditation;

(3) Pay all relevant fees;

(4) Participate in proficiency testing as required.

(5) Be capable of performing the tests for which it is accredited according to the latest version of the test method within one year after its publication or within another time limit specified by the Director of OPSP;

(6) Limit the representation of the scope of its accreditation to only those tests or services for which accreditation is granted;

(7) Limit all its test work or services for clients to those areas where competence and capacity are available;

(8) Limit advertising of its accredited status to letterheads, brochures, test reports, and professional, technical, trade, or other 1aboratory services publications, and use the NVLA.P logo under guidance provided by the Director of OPSP;

(9) Inform its clients that the laboratory's accreditation or any of its test reports in no way constitutes or implies product certification, approval, or endorsement by NBS;

(10) Maintain records of all actions taken in response to testing complaints for a minimum of one year; 
(11) Maintain an independent decisional relationship between itself and its clients, affiliates, or other organizations so that the laboratory's capacity to render test reports objectively and without bias is not adversely affected;

(12) Report to the Director of OPSP within 30 days any major changes involving the location, ownership, management structure, authorized representative, approved signatories, or facilities of the laboratory; and

(13) Return to the Director of OPSP the certificate of accreditation for possible revision or other action should it:

(i) be requested to do so by the Director of OPSP;

(ii) voluntarily terminate its accredited status; or

(iii) become unable to conform to any of these conditions or the applicable criteria of Section 7.33 and related technical requirements.

(b) To become accredited and maintain accreditation, a laboratory shall supply, upon request, the following information:

(1) Legal name and full address;

(2) Ownership of the 1 aboratory;

(3) Organization chart defining relationships that are relevant to performing testing covered in the accreditation request;

(4) General description of the laboratory, including its facilities and scope of operation;

(5) Name and telephone number of the authorized representative of the 1 aboratory;

(6) Names or titles and qualifications of laboratory staff nominated to serve as approved signatories of test reports that reference NVLAP accreditation; and

(7) Other information as may be needed for the specific LAP(s) in which accreditation is sought.

Sec. 7.33 Criteria for accreditation.

(a) Quality System. (1) The laboratory shall operate under an internal quality assurance program appropriate to the type, range, and volume of work performed. The quality assurance program must be designed to ensure the required degree of accuracy and precision of the laboratory's work and should include key elements of document control, sample control, data validation, and corrective action. The quality assurance program must be documented in a quality manual or equivalent (e.g., operations notebook) which is available for use by laboratory staff. A person(s) must be identified as having responsibility for maintaining the quality manual.

(2) The quality manual must include as appropriate:

(i) The laboratory's quality assurance policies including procedures for corrective action for detected test discrepancies;

(ii) Quality assurance responsibilities for each function of the laboratory;

(iii) Specific quality assurance practices and procedures for each test, type of test, or other specifically delineated function performed;

(iv) Specific procedures for retesting, control charts, reference materials, and interlaboratory tests; and

(v) Procedures for dealing with testing complaints.

(3) The laboratory shall periodically review its quality assurance system by or on behalf of management to ensure it's continued effectiveness. These reviews must be recorded with details of any corrective action taken. 
(b) Staff. (1) The laboratory sha11:

(i) Be staffed by individuals having the necessary education, training, technical knowledge, and experience for their assigned functions; and

(ii) Have a job description for each professional, scientific, supervisory and technical position, including the necessary education, training, technical knowledge, and experience.

(2) The laboratory shall document the test methods each staff member has been assigned to perform.

(3) The laboratory shall have a description of its training program for ensuring that new or untrained staff are able to perform tests properly and uniformiy to the requisite degree of precision and accuracy.

(4) The laboratory shall be organized:

(i) So that staff members are not subjected to undue pressure or inducement that might influence their judgment or results of their work; and

(ii) In such a way that staff members are aware of both the extent and the limitation of their area of responsibility.

(5) The laboratory shall have a technical manager (or similar title) who has overall responsibility for the technical operations of the 1 aboratory.

(6) The laboratory shall have one or more signatories approved by the Director of OPSP to sign test reports that reference NVLAP accreditation. Approved signatories shall:

(i) Be competent to make a critical evaluation of test results; and

(ii) Occupy positions within the laboratory's organization which makes them responsible for the adequacy of test results.

(c) Facilities and Equipment. (1) The laboratory shall be furnished with all items of equipment and facilities for the correct performance of the tests and measurements for which accreditation is granted and shall have adequate space, lighting, and environmental control, and monitoring to ensure compliance with prescribed testing conditions.

(2) All equipment must be properly maintained to ensure protection from corrosion and other causes of deterioration. Instructions for a proper maintenance procedure for those items of equipment which require periodic maintenance must be available. Any item of equipment or component thereof which has been subjected to overloading or mishandling, gives suspect results, or has been shown by calibration or otherwise to be defective, must be taken out of service and clearly labelled until it has been repaired. When placed back in service, this equipment must be shown by test or calibration to be performing its function satisfactorily.

(3) Records of each major item of equipment must be maintained. Each record must include:

(i) The name of the item of equipment;

(ii) The manufacturer's name and type, identification and serial number;

(iii) Date received and date placed in service;

(iv) Current location, where appropriate;

(v) Details of maintenance; and

(vi) Date of last calibration, next calibration due date, and calibration report references. 
(d) Calibration. The laboratory shall:

(1) Calibrate new testing equipment before putting it into service;

(2) Recalibrate, at regular intervals, in-service testing equipment with the calibration status readily available to the operator:

(3) Perform checks of in-service testing equipment between the regular calibration intervals, where relevant;

(4) Maintain adequate records of all calibrations and recalibrations; and

(5) Provide traceability of all calibrations and reference standards of measurement where these standards exist. Where traceability of measurements to primary (national or international) standards is not applicable, the laboratory shall provide satisfactory evidence of the accuracy or reliability of test results (e.g., by participation in a suitable program of interlaboratory comparison).

(e) Test Methods and Procedures. The 1aboratory shall:

(1) Conform in all respects wi th the test methods and procedures required by the specifications against which the test item is to be tested, except that whenever a departure becomes necessary for technical reasons the departure must be acceptable to the client and recorded in the test report;

(2) Have data to prove that any departures from standard methods and/or procedures due to apparatus design or for other reasons do not detract from the expected or required precision of the measurement;

(3) Maintain a test plan for implementing testing standards and procedures including adequate instructions on the use and operation of all relevant equipment, on the handling and preparation of test items (where applicable), and on standard testing techniques where the absence of such instructions could compromise the test. All instructions, testing standards, specifications, manuals, and reference data relevant to the work of the laboratory must be kept up-to-date and made readily available to the staff;

(4) Maintain measures for the detection and resolution of in-process testing discrepancies for manual and automatic test equipment and electronic data processing equipment, where applicable;

(5) Maintain a system for identifying samples or items to be tested, which remains in force from the date of receipt of the item to the date of its disposal, either through documents or through marking to ensure that there is no confusion regarding the identity of the samples or test items and the results of the measurements made; and

(6) Maintain rules for the receipt, retention, and disposal of test items, including procedures for storage and handiing precautions to prevent damage to test items which could invalidate the test results. Any relevant instructions provided with the tested item must be observed.

(f) Records. The laboratory shall:

(1) Maintain a record system which contains sufficient information to permit verification of any issued report;

(2) Retain all original observations, calculations and derived data, and calibration records for one year unless a longer period is specified; and

(3) Hold records secure and in confidence, as required. 
(g) Test Reports. (1) The laboratory shall issue test reports of its work which accurately, clearly, and unambiguously present the specified test results and all required information. Each test report must include the following information as applicable:

(i) Name and address of the laboratory;

(ii) Identification of the test report by serial number, date, or other appropriate means;

(iii) Name and address of client;

(iv) Description and identification of the test specimen, sample, or lot of material represented;

(v) Identification of the test specification, method, or procedure used;

(vi) Description of sampling procedure, if appropriate;

(vii) Any deviations, additions to, or exclusions from the test specifications;

(viii) Measurements, examinations, and derived results supported by tables, graphs, sketches, and photographs, as appropriate, and any failures identified;

(ix) A statement of measurement uncertainty where relevant;

$(x)$ Identification of the organization and the person accepting technical responsibility for the test report and date of issue;

(xi) A statement that the report must not be reproduced except in full with the approval of the 1aboratory; and

(xii) A statement to the effect that the test report relates only to the items tested.

(2) The laboratory shall issue corrections or additions to a test report only by a further document suitably marked, e.g. "Supplement to test report serial number .....," which meets the relevant requirements of Section $7.33(\mathrm{~g})(1)$.

(3) The laboratory shall retain a copy of each test report issued for one year unless a longer period is specified by the Director of OPSP.

(4) The laboratory shall ensure that all test reports endorsed with the NVLAP logo are signed by an approved signatory. 



\section{INFORMING THE PUBLIC OF YOUR ACCREDITATION STATUS}

\section{Summary}

This Bulletin supersedes NVLAP Lab Bulletin No. 3 dated October 1, 1981. It reflects significant changes made to the NVLAP procedures (Title 15, Part 7, of the Code of Federal Regulations) which became effective on December 10, 1984.

The Bulletin is addressed primarily to personnel at accredited laboratories who are responsible for communicating the laboratory's accreditation status to clients and the public, through advertising, issuance of test reports, use of the NVLAP logo, etc.

The Bulletin's purpose is to "provide guidance on referencing the laboratory's accredited status, and use of the NVLAP logo by the laboratory and its clients," in accordance with provisions of the NVLAP Procedures.

\section{Background}

NVLAP was established to assist industry and government in identifying competent testing laboratories. NVLAP accreditation means that a laboratory is competent to perform specific test methods in selected fields of testing. The NVLAP Procedures are the bases upon which the entire program operates and accomplishes accreditation of laboratories. Parts A and B of the Procedures provide general information and the method by which a new Laboratory Accreditation Program (LAP), in a new field of testing, may be requested and established. Parts $C$ and $D$ of the Procedures, of more concern to accredited laboratories, describe how a laboratory becomes accredited and the conditions and criteria for initial and continued accreditation. This Bulletin is concerned principally with issues in Part D of the Procedures. 
Lab Bulletin No. 3A

Page 2

January 1, 1985

Requirements and Guidance

To become accredited and maintain accreditation a laboratory shall:

limit the representation of the scope of its accreditation to only those tests or services for which accreditation is granted

A laboratory accredited by NVLAP may use the following statement on its letterheads and in trade or other publications: "Accredited by the National Bureau of Standards, National Voluntary Laboratory Accreditation Program for selected test methods for --(identify product or service area(s))." This statement could, for example, be placed at the bottom of the laboratory letterhead.

A laboratory's letterhead containing a reference to its NVLAP accreditation may be used in any direct solicitation for business from potential customers. It is recommended that a copy of the NVLAP Certificate and Scope of Accreditation be appended to such a solicitation.

To become accredited and maintain accreditation a laboratory shall:

limit advertising of its accredited status to letterheads, brochures, test reports, and professional, technical, trade, or other laboratory services publications, and use the NVLAP logo under guidance provided by NBS

A statement about NVLAP accreditation and the NVLAP logo may be used on reports and data sheets containing test data obtained by a laboratory provided the tests or services are performed in accordance with the terms of its accreditation. The NVLAP logo may not be used on test reports or data sheets during any period of suspended or expired accreditation or after voluntary or involuntary termination of accreditation.

The nature or type of product advertising prohibited by NVLAP procedures includes any advertising that is intended to encourage a consumer to purchase a product because it was tested by an accredited laboratory, whether that advertising appears in consumer media, the business media, or at a point of sale to consumers.

News stories and advertising by laboratories of their accredited status in the trade press is not only permissible but encouraged. The use of advertisements in the trade press is consistent with NVLAP procedures.

The "consumer media" to be avoided include popular periodicals such as Time, Good Housekeeping, etc., and newspapers such as the Washington Post or the New York Times. The term "consumer media" does not include business publications such as Barron's, or the Wall Street Journal which are oriented to the business community and in which products per se normally are not advertised. 
Lab Bulletin No. $3 \mathrm{~A}$

Page 3

January 1, 1985

To become accredited and maintain accreditation a laboratory shall:

inform its clients that the laboratory's accreditation or any of its test reports in no way constitutes or implies product certification, approval, or endorsement by NBS

Laboratory accreditation by NBS confers recognition that a laboratory has been found competent to perform specific test methods or services in a selected field(s) of testing. Laboratories must avoid all inference that accreditation under NVLAP carries with it an endorsement, approval, or recommendation of the products tested by the laboratories.

To become accredited and maintain accreditation a laboratory shall:

assure that all test reports endorsed with the NVLAP logo are signed by an approved signatory

An approved signatory is an officer or employee of the laboratory, identified by name or position, who has been accepted by NVLAP as being responsible for the issuance of test reports under this condition of NVLAP accreditation. A laboratory seeking initial accreditation or reaccreditation must specify (a) one or more individuals, or (b) position(s) within the organization for which it requests acceptance as an approved signatory.

Computer or machine generated test reports that contain the NVLAP logo need not be signed but must have the printed name of the approved signatory.

\section{Questions About Accreditation}

If you have questions about what is an acceptable method of advertising in areas not specifically covered in this Lab Bulletin or about the propriety or acceptability of a particular statement, advertising media, or use of information about your NVLAP accreditation status, please contact NVLAP before your publicity program is implemented.

Ca11 301-921-3431 or

Send your questions to:

Harvey W. Berger

Associate Manager, Laboratory Accreditation

National Bureau of Standards

ADMIN A531

Gaithersburg, MD 20899 

National Voluntary Laboratory Accreditation Program

(NVLAP)

\section{ACOUSTICAL TESTING SERVICES \\ (ACOUSTICS LAP) \\ Test Method List}

See explanation of notes at end of Test Method listing.

Test Method

Designation

ANSI/ASTM C367-78

ANSI/ASTM C384-77

ANSI/ASTM C423-84a

ASTM C522-80

ASTM C523-68 (81)

* ANSI/ASTM E90-83

ANSI/ASTM E492-77

ANSI/ASTM E596-78

* ASTM E756-83

* ANSI S1.31-80 1

* ANSI $51.32-802$

* ANSI $\$ 1.35-791$

* ISO $3741-751$

* ISO $3742-753$

* ISO $3745-77$ I
Short Title

\section{PRECISION MEASUREMENTS}

Strength Properties, Prefabricated

Architectural Acoustical Materials

Impedance and Absorption of Acoustical Materials

Sound Absorption and Sound Absorption Coefficients

Airflow Resistance of Acoustical Materials

Light Reflectance of Acoustical Materials

Airborne Sound Transmission Loss of Building Partitions

Impact Sound Transmission Through Floor-Ceiling

Assemblies

Noise Reduction of Sound-Isolating Enclosures

Vibration Damping Properties of Materials

a. Sound Power Levels, Broad-Band Noise

Sources in Reverberation Rooms

b. (direct method only)

c. (comparison method on $1 y$ )

Sound Power Leve1s, Discrete- Frequency and

Narrow-Band Noise Sources in Reverberation Rooms

a. Sound Power Levels, Noise Sources in Anechoic and Hemi-Anechoic Rooms

b. (anechoic room method on $1 y$ )

c. (hemi-anechoic room method on 1y)

a. Sound Power Levels, Broad-Band Sources in Reverberation Rooms

b. (direct method only)

c. (comparison method only)

Sound Power Levels, Discrete-Frequency and

Narrow-Band Sources in Reverberation Rooms

a. Sound Power Levels, of Noise Sources in Anechoic and Semi-Anechoic Rooms

b. (anechoic room method only)

c. (semi-anechoic room method only) 


\section{ENGINEERING MEASUREMENTS}

\author{
ANSI B71.1-80 \\ (para. 9) \\ ANSI S1.29-79 4 \\ * ANSI S1.34-80 \\ * ANSI S3.19-75 \\ ANSI S5.1-71
}

ISO $362-81$

ISO $512-79$

ISO $3744-81$

ISO $5130-82$

SAE J192a-80

SAE J1161-80

Title 40, CFR, Part 205

AMCA Test Code 300-1967

AMA-1-II -675

EEC 81/334 (Annex I, para. 5.2) 6

EEC 70/388 (Annex I, paras. 1.2.1, $1.2 .2,1.2 .3$, and 2)

TRIAS 20-1980 7

TRIAS 21-1979 7

ECE Regulation

No. 288
Sound Level Tests; Power Lawn Mowers, Lawn and Garden Tractors and Lawn Tractors

Measurement of Noise Emitted by Computer and Business Equipment

Sound Power Levels, Noise Sources over a Reflecting Plane

Noise Protection, Hearing Protectors and Earmuffs

a. Measurement of Sound from Pneumatic Equipment

b. (small machines only)

c. (portable compressors and large items of pneumatic plants only)

d. (stationary plant equipment only)

Noise Emitted by Accelerating Road Vehicles

Sound Pressure Levels, Vehicle Signaling Devices

Sound Power Levels of Noise Sources Over a Reflecting Plane

Noise Emitted by Stationary Road Vehicles

Exterior Sound Level of Snowmobiles

Sound Level Measurement Procedure for Snow Vehicles

a. Transportation Equipment Noise Emission Measurements

b. (Subpart B only)

c. (Subpart D only)

d. (Subpart E only)

e. (Subpart F only)

Test Code for Sound Ratings

Ceiling Sound Transmission Test by Two-Room Method Sound Levels of Motor Vehicles

Type Approval of an Audible Warning Device

Noise Test Procedures for Motor Vehicles

Horn Sound Level Test Procedure for Motor Vehicles Sound Levels of Vehicle Audible Warning Devices 
Notes:

1. The laboratory will be accredited for only the frequency range for which its test room is qualified.

2. Accreditation for this test method also requires accreditation for ANSI S1.31. Also, accreditation for ANSI S1.32 will be only for the frequency range for which the laboratory's test room is qualified.

3. Accreditation for this test method also requires accreditation for ISO 3741 . Also, accreditation for ISO 3742 will be only for the frequency range for which the laboratory's test room is qualified.

4. Accreditation for this test method also requires accreditation for one or more of the following methods. ISO 3741, ISO 3742, ISO 3744, and ISO 3745.

5. Adopted by the Ceiling and Interior Systems Contractors Association

6. Council of European Communities

7. Ministry of Transport - Japan Automobile Importation Association

8. United Nations regulation

* Periodic proficiency testing may be required 


\begin{tabular}{|c|c|c|c|}
\hline $\begin{array}{l}\text { U.S. DEPT. OF COMM. } \\
\text { BIBLIOGRAPHIC DATA } \\
\text { SHEET (See instructions) }\end{array}$ & $\begin{array}{l}\text { 1. PUBLICATION OR } \\
\text { REPORT NO. } \\
\text { NBSIR-85/3199 }\end{array}$ & 2. Performing Organ. Report No. & $\begin{array}{l}\text { 3. Publication Date } \\
\text { July } 1985\end{array}$ \\
\hline \multicolumn{4}{|c|}{$\begin{array}{l}\text { 4. TITLE AND SUBTITLE } \\
\text { Acoustics LAP Handbook } \\
\text { Operational and Technical Requirements for the Laboratory Accreditation } \\
\text { Program for Acoustical Testing Services }\end{array}$} \\
\hline \multicolumn{4}{|c|}{$\begin{array}{l}\text { 5. AUTHOR(S) } \\
\text { Robert L. G? adhill, Wiley A. Hall Jr., Jeffrey Horlick, Harvey W. Berger }\end{array}$} \\
\hline \multicolumn{3}{|c|}{ 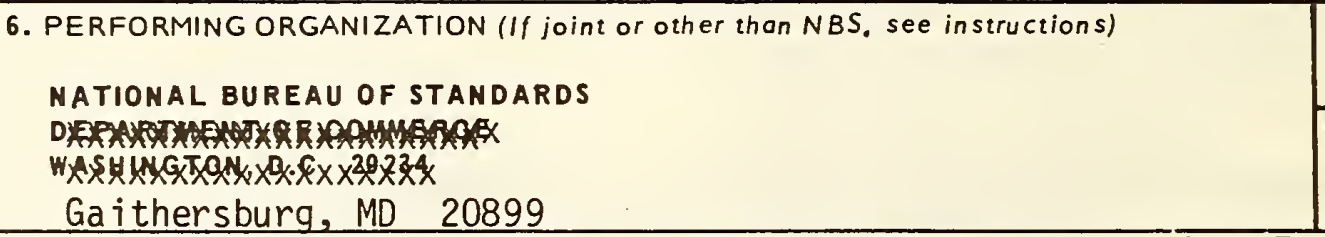 } & $\begin{array}{l}\text { 7. Contract/Grant No. } \\
\text { 8. Type of Report \& Period Covered }\end{array}$ \\
\hline
\end{tabular}

9. SPONSORING ORGANIZATION NAME AND COMPLETE ADDRESS (Street, City。 Stote, ZIP)

10. SUPPLEMENTARY NOTES

Document describes a computer program; SF-185. FIPS Software Summary, is attached.

11. ABSTRACT (A 200-word or less factual summary of most significant information. If document includes a significant bibliography or literature survey. mention it here)

This document explains the operational and technical requirements of the Laboratory Accreditation Program (LAP) for Acoustics (Acoustics LAP). A11 of the steps leading to accreditation are discussed. Technical requirements are explained indicating how the NVLAP criteria are applied.

It is intended for use by staff of accredited laboratories, those seeking accreditation, other laboratory accreditation systems, and others needing information on the requirements for NVLAP accreditation under this LAP.

12. KEY WORDS (Six to twelve entries: alphabetical order: copitalize only proper names; and separate key words by semicolons) accreditation; acoustics; assessment; laboratory; proficiency testing

13. AVAILABILITY

$[\mathrm{X}]$ Unlimited

$\square$ For Official Distribution. Do Not Release to NTIS

Order From Superintendent of Documents, U.S. Government Printing Office, Washington. D.C. 20402.

X] Order From National Technical Information Service (NTIS), Springfield, VA. 22161
14. NO. OF

PRINTED PAGES

31

15. Price

$$
\$ 8.50
$$


